\title{
Immunohistochemistry contribution in the diagnosis of splenic marginal zone lymphoma
}

\author{
(D) Juliene Lima Mesquita ${ }^{1}$ \\ Yensy Mariana Zelaya Rosales ${ }^{1}$ \\ (i) Yhasmine Delles Oliveira Garcia ${ }^{1}$ \\ (iD) Francisco Dario Rocha Filho ${ }^{2}$ \\ Beatriz Stela Gomes de Sousa Pitombeira Araujo ${ }^{2}$ \\ (iD) oão Paulo de Vasconcelos Leitão ${ }^{2}$ \\ (iD) Jesus Irajacy Costa \\ (D) Beatrice Araújo Duarte ${ }^{3}$ \\ (D) João Vitor Araújo Duarte ${ }^{3}$ \\ Romélia Pinheiro Gonçalves Lemes 4 \\ (D) Fernando Barroso Duarte ${ }^{5}$
}

\begin{abstract}
1. Programa de Pós-Graduação em Ciências Farmacêuticas da Universidade Federal do Ceará. Fortaleza, Ceará, Brasil. 2. Médico no Serviço de Hematologia, Hospital Universitário Walter Cantídio, Fortaleza, Ceará. Brasil. 3. Estudante de Medicina no Centro Universitário Christus. Fortaleza. Ceará. Brasil. 4. Professor, Departamento de Análises Clínicas, Faculdade de Farmácia, Universidade Federal do Ceará. Fortaleza, Ceará, Brasil. 5. Professor do Departamento de Cirurgia e Diretor do Serviço de Transplante de Medula Óssea da Universidade Federal do Ceará. Fortaleza, Ceará, Brasil
\end{abstract}

Dear Editor,

Splenic marginal zone B-cell lymphoma is a rare type of non-Hodgkin B-cell lymphoma, without preference for sex, which affects individuals mainly over 50 years. In many cases, the disease is asymptomatic, with absent splenomegaly and lymphadenomegaly. The changes in the peripheral blood, when present, are lymphocytosis, anemia, and thrombocytopenia; cytopenias are mostly due to hypersplenism. The presence of B symptoms and increased LDH is rare ${ }^{1,2}$. The immunophenotype pattern is characterized by pan-B cell expression with positive CD19, CD20, CD22, CD79a, IgM, and IgD. CD5 is found only in $15 \%$, and CD23 in 30\% of cases. It presents as the most common cytogenetic alteration the heterogeneous expressions of chromosome 7, the (9:14) (p13: q32), which overlaps the IgH and PAX-5 $5^{3}$ genes. The marrow infiltration patterns are highly variable and consist of nodular, paratrabecular, and interstitial ${ }^{4,5}$. The finding of the intrasinusoidal pattern is more easily observed by CD2O or CD34 immunohistochemistry. Spleen histology shows micronodular infiltration of white pulp with biphasic pattern and a variable degree of red pulp involvement. Differential diagnosis should be made with other chronic B7 cell lymphoproliferative diseases ${ }^{5}$.

The clinical course is mostly indolent with a median global survival of 10 years. There is no standard therapy; so, splenectomy is the most used 
therapeutic approach since it helps in diagnosis as well as in the improvement of symptoms related to cytopenias. Other therapies using chlorambucil or cyclophosphamide, alone or in combination with other agents (CVP, CHOP), have limited results. Immunotherapy with an anti-CD2O antibody is a molecular target for the treatment of non-Hodgkin B cell lymphoma with CD2O positive protein ${ }^{6,7}$. Results of anti-CD2O monotherapy demonstrated a 17-month duration of response and global survival of $80 \%$ up to 6 years and progression-free survival of $60 \%$ up to 4 years.

We report the case of a patient with splenic marginal zone lymphoma with positive markers for B-lymphocytes, who presented asymptomatic and with splenomegaly, and review some aspects related to this disease.

A 50-year-old male, businessman, from Fortaleza

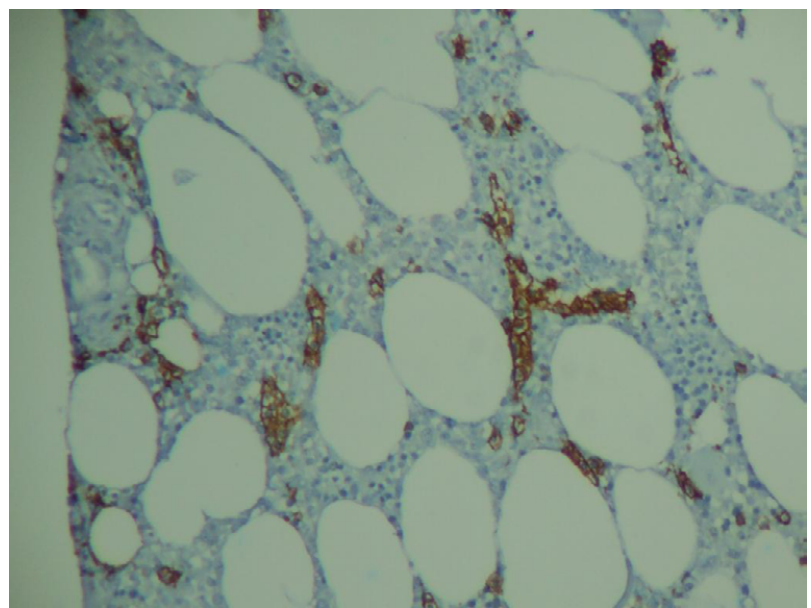

FIGURE 1. INTRASINUSOIDAL MEDIAL INFILTRATION BY SPLENIC MARGINAL ZONE NHL-B (CD2O +) (200X IMMUNOHISTOCHEMICAL STUDY)

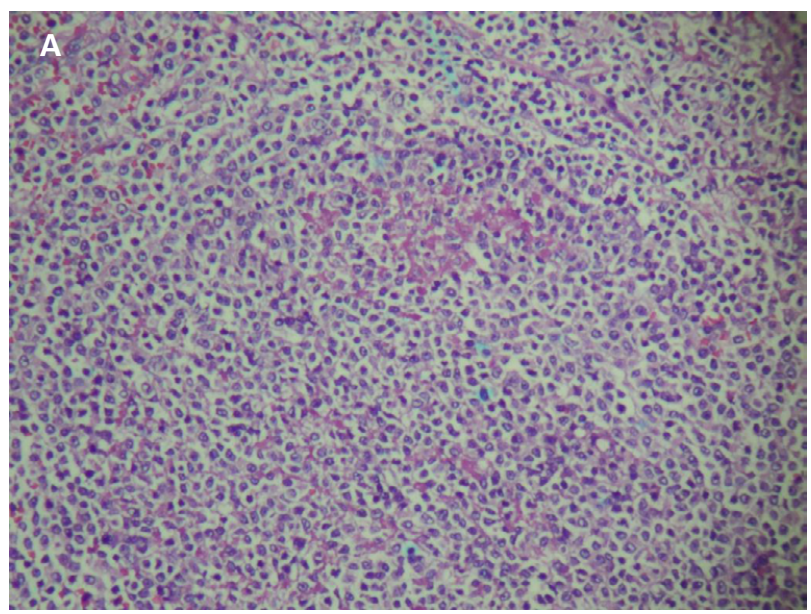

(CE), presented, in 2019, at a hematology service unit asymptomatic with splenomegaly and blood count results within normal limits. A bone marrow biopsy presented normal results for hematoxylin-eosin (HE), but immunohistochemistry was positive for CD2O in sinusoid, diagnosed with marginal zone lymphoma (Figure 1). A significant white and red pulp labeling for CD20 was observed, while the markers CD5, CD3, cyclin D1, BCL-6, and CD10 were not significant. CD23 marks dendritic and Ki67 follicular cells in 30\% of the cells; normal cytogenetics. Splenectomy was performed with the anatomopathological study of the spleen (Figures 2), and the diagnosis was confirmed as marginal splenic zone lymphoma. The first recovery cycle was started and has shown stability and no toxicity until now.

Splenic marginal zone lymphoma infiltrated into the bone marrow, usually used with multiple patterns and usually forming lymphoid nodules with germinal centers; the cellular pattern is similar to the initial site. The sinusoidal pattern is strongly associated with marginal zone lymphoma; however, the most recent reports have shown that this pattern is very nonspecific, rarely happens as the only infiltration pattern and that immunohistochemistry is necessary to identify the infiltrations.

We presented a case that reinforces the importance of anatomopathological examination of the bone marrow, whenever possible, complementary to other laboratory tests (peripheral blood, cytogenetics, immunophenotyping, and molecular), as well as the study of immunohistochemistry and interpretation in

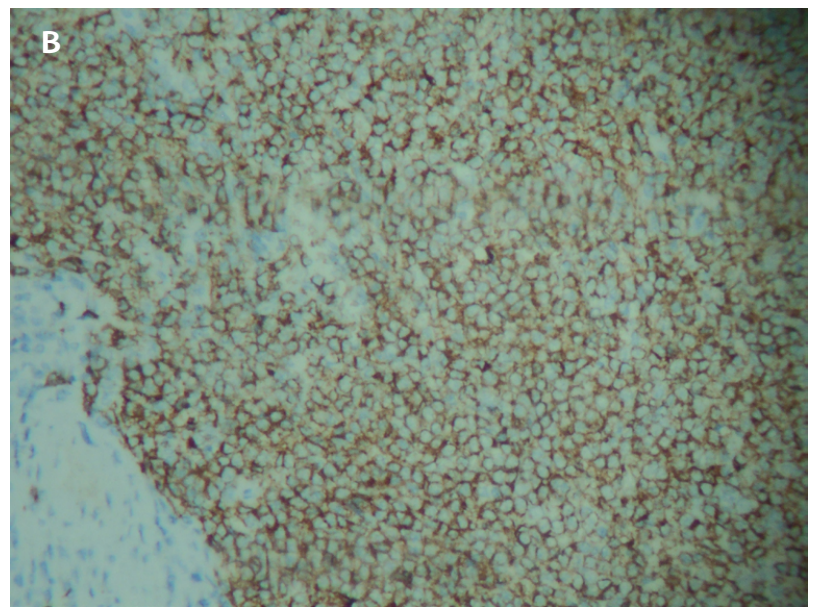

FIGURE 2. A: MARGINAL ZONE SPLENIC NON-HODGKIN'S LYMPHOMA, NODULAR ASPECT (HE 20OX). B: SPLENIC LNH-B, FROM THE MARGINAL ZONE WITH STRONG EXPRESSION OF CD2O (200X IMMUNOHISTOCHEMICAL STUDY) 
the clinical context. Anatomopathological examination of the spleen was also important to define the diagnosis of splenic marginal zone lymphoma.

\section{Conflict of interest}

The authors have no conflict of interest to declare.

\section{REFERENCES}

1. Zinzani PL. The many faces of marginal zone lymphoma. Hematology Am Soc Hematol Educ Program. 2012;2012:426-32.

2. Arcaini $L$, Rossi $D$, Paulli M. Splenic marginal zone lymphoma: from genetics to management. Blood. 2016;127(17):2072-81.

3. Swerdlow SH, Campo E, Harris NL, Jaffe ES, Pileri SA, Stein H, et al.; International Agency for Research on Cancer, World Health Organization. WHO classification of tumours of haematopoietic and lymphoid tissues. $4^{\text {th }}$ ed. Lyon: International Agency for Research on Cancer; 2008.

4. Santos TSD, Tavares RS, Farias DLC. Splenic marginal zone lymphoma: a literature review of diagnostic and therapeutic challenges. Rev Bras Hematol

Hemoter. 2017;39(2):146-54.

5. Kent SA, Variakojis D, Peterson LC. Comparative study of marginal zone lymphoma involving bone marrow. Am J Clin Pathol. 2002;117(5):698-708.

6. Behdad A, Bailey NG. Diagnosis of splenic B-cell lymphomas in the bone marrow: a review of histopathologic, immunophenotypic, and genetic findings. Arch Pathol Lab Med. 2014;138(10):1295-301.

7. Debiasi M, Hehnemann M, Garicochea B. Rituximab monotherapy for splenic marginal zone lymphoma with villous lymphocytes: report on longterm disease control for two patients with recurrence after splenectomy. Sao Paulo Med J. 2010;128(6):375-7. 